\title{
Hacia una definición del papel de Quevedo en Italia
}

\author{
Federica Cappelli \\ Dipartimento di Filologia, Letteratura e Linguistica \\ Università di Pisa \\ Piazza Torricelli, 2 \\ 56126 Pisa \\ Italia \\ federica.cappelli@unipi.it
}

[La Perinola, (Issn: 1138-6363), 21, 2017, pp. 17-40]

DOI: $10.15581 / 017.21 .17-40$

\section{Estado de LA CUESTión}

Intentar una definición del papel que don Francisco de Quevedo jugó en Italia durante los dos virreinatos del duque de Osuna parece ser una tarea tan atrayente como compleja: la enorme cantidad de ensayos que versan sobre el tema es una prueba indudable de la afición que ha llevado a muchos estudiosos a investigar este aspecto de la biografía de nuestro autor que, sin embargo, queda aún en parte oscuro. Las razones de esta atención, casi morbosa, hacia los años italianos de don Francisco quizá haya que buscarlas, en primer lugar, en su repentino abandono de la pluma y en el consiguiente alejamiento de los círculos culturales (especialmente napolitanos) para entregarse por completo a asuntos político-diplomáticos; en segunda instancia, en el mito que se vino a crear alrededor del escritor, sobre todo en relación a su participación en la supuesta conjura antiveneciana de mayo de 1618.

De la primera razón que hemos aducido procede tanto cierta obstinada pretensión de encontrar obras ignoradas de Quevedo, atribuibles a la etapa italiana, como un inagotable afán de aclarar, de una vez por todas, la función que el escritor desempeñó al servicio del duque de Osuna. La profusión de estudios acerca de la posible paternidad quevediana del Aviso de Parnaso anónimo antiveneciano, titulado La República de Venecia llega al Parnaso y refiere a Apolo el estado en que se halla (1617), parece ser el testimonio principal de la tenaz resistencia de muchos investigadores a aceptar el silencio del Quevedo literato en el periodo transcurrido en Italia. A partir de las primeras referencias a la existencia del libelo, los estudiosos se han enfrentado con el difícil 
problema de su autoría: Fernández-Guerra ${ }^{1}$, el primero en publicar un extracto del aviso, no se atreve a expresar juicios definitivos, mientras que Astrana Marín ${ }^{2}$, quien por primera vez imprime la obrita completa, no duda en atribuirla a Quevedo, pero la incluye, prudentemente, entre las obras de probable autenticidad. Se trata, en efecto, de una cuestión todavía abierta, que ha dividido desde siempre a la crítica en dos bandos opuestos: por un lado, los favorables a la paternidad quevediana del panfleto - entre ellos Marañón, Williams, Martinengo, Forti, Juárez, Hendrix y, en tiempos mucho más recientes, Gagliardi ${ }^{3}-$ y, por el otro, los escépticos, como Blanco, Jauralde y quien escribe estas líneas ${ }^{4}$. Si los primeros no alcanzan, no obstante los argumentos exhibidos tanto de carácter interno como externo, conclusiones satisfactorias ni resolutivas, los segundos mantienen la inoportunidad de incluir definitivamente el aviso entre las obras de don Francisco, bien porque no hay pruebas persuasivas ni concluyentes que permitan arrojar plena luz sobre la identidad del anónimo libelista (Cappelli, Jauralde) o bien porque existen razones internas por las que es imposible afirmar tal autoría (Blanco).

Por lo que respecta a la urgencia de esclarecer el papel de Quevedo al servicio de don Pedro Girón, sería imposible extendernos aquí en un recuento completo de la bibliografía existente, al tratarse de un tema sobre el que se han vertido auténticos ríos de tinta. A partir de los primeros acercamientos de Pérez Bustamante para acabar con la más reciente, monumental, biografía de Jauralde, pasando por los iluminadores trabajos de Crosby y, sucesivamente, los de Reglá, López Ruiz, la monografía de Juárez, las numerosas y, en parte, muy actuales aportaciones de Martinengo ${ }^{5}$, por citar solo algunos, el papel de nuestro autor en Italia se ha ido perfilando cada vez más. Gracias a investigaciones rigurosas y al descubrimiento de datos $\operatorname{concretos}^{6}$, nos hemos apartado,

1. Obras de Francisco de Quevedo, tomo XLVIII, pp. 642-643 y pp. 650-653.

2. Quevedo, Obras completas, vol. II, pp. 980-985.

3. Marañón, 1946; Williams, 1946; Martinengo, 1977 y 2007; Forti, 1989; Juárez, 1990; Hendrix, 1995 y Gagliardi, 2011; esta última, a pesar de anunciar «Nuevos datos sobre la aparición y circulación de la República de Venecia) (Gagliardi, 2011, p. 564), tampoco consigue zanjar la cuestión por aducir argumentos tan débiles como poco persuasivos; en su estudio se da cuenta de la presencia de un nuevo ejemplar manuscrito del aviso en la Biblioteca Vaticana (ms. Ott. Lat. 1100), al que añado yo el reciente hallazgo, por parte del colega pisano Michele Olivari, en la Biblioteca Universitaria de Barcelona, de un "voluminoso cartapacio» (Ms. 1008, fols. 250r y ss.) recopilado por el dominico Gaspar Vicens, que incluye un nuevo ejemplar manuscrito de La República de Venecia que presenta varias omisiones, una añadidura y un título distinto: Papel que se publicó en Madrid el año 1617 que era cuando había guerra entre España y el Saboyano, al cual favorecían muchos Príncipes y en particular la Señoría de Venecia (Olivari, 2014, pp. 451-452).

4. Ver Blanco, 1998, Jauralde, 1998 y Cappelli 2001, 2003 y 2011.

5. Ver Pérez Bustamente, 1933 y 1945; Crosby, 1955, 1956, 1958a, 1958b, 2005; Reglá, 1956; López Ruiz, 1985 y 2008; Martinengo, 1977, 1983, 2007, 2015a y 2015b; Juárez, 1990 y Jauralde, 1998.

6. Ver Beladiez, 1954 y Crosby, 1955, 1956, 1958b y 2005. 
poco a poco, de la visión fabulosa ${ }^{7}$ que de don Francisco había concebido su primer biógrafo, Paolo Tarsia; visión, esta, perpetuada luego por Mérimée y Astrana Marín 8

Hay que considerar, además, que, aparte de los trabajos expresamente dedicados al asunto como los que venimos citando, cualquier otro estudio que roce el tema italiano, sea este de enfoque literario o histórico, se detiene también en comentar el compromiso de nuestro autor en Italia aportando su propia definición del cargo que él pudo desempeñar al servicio de Osuna. De aquí un sinfín de definiciones de entre las cuales destacan las que se caracterizan por repetirse constantemente: claro indicio de cierta concordancia de opiniones entre los críticos. Me refiero a la imagen de Quevedo como hombre de confianza, secretario, agente, consejero político y emisario de Osuna, que se encuentra, entre otros, en los trabajos de Peraita, Jauralde, Biurrun Lizarazu, Linde, Ettinghausen, Martinengo 9.

Más sugestivos, pero menos compartidos por los estudiosos y evidentemente procedentes de la ya aludida interpretación mítica de la misión de Quevedo en las dos cortes virreinales, son los epítetos de nigromante, mago u oculto consejero de Osuna que pueblan crónicas, documentos y panfletos coetáneos, como los dispacci del residente veneciano en Nápoles, Gasparo Spinelli, o el Castigo essemplare de' calunniatori de Giacomo Castellani ${ }^{10}$. Se trata de una interpretación que la crítica moderna (Crosby, Jauralde, Martinengo ${ }^{11}$ ) ha explorado atentamente y ha rechazado por atribuirla a la reputación ambigua que de Quevedo circulaba en el sur italiano, a raíz de su interés intelectual por las hoy llamadas ciencias ocultas; interés, este, finalizado únicamente, en realidad, al control del panorama cultural del virreino: como recuerda Martinengo, Osuna delegó a don Francisco «la tarea de actuar una política cultural que fuera al mismo tiempo respetuosa de las exigencias de los intelectuales y garantizadora del status quo políticom, lo cual le obligó a profundizar también «en una orientación especulativa» ${ }^{12}$ que preveía la curiosidad por la astrología, la magia y la alquimia; de ahí, pues, su fama equívoca, que circulaba especialmente en los ambientes provenecianos.

En esos mismos ambientes es donde se fragua, además, el mito de la implicación de Quevedo en la presunta conjura de los españoles contra Venecia: otro tema que hemos considerado como subyacente al persistente interés de la crítica por la experiencia italiana de don Francisco.

7. Según refiere Juárez, en efecto, cuando Tarsia «carece de datos concretos prefiere usar una estructura de tipo temático optando por la "verosimilitud retórica" frente a la verdad histórica» (1990, p. 45).

8. Ver Merimée, 1886 y Astrana Marín, 1945.

9. Ver Peraita, 1997, pp. 182-183; Jauralde, 1998, p. 303; Biurrun Lizarazu, 2000, p. 15; Linde, 2005, p. 110; Ettinghausen, 2006, p. 73 y 2011, p. 2; Martinengo, 2006 y 2015b, p. 36.

10. Ver Fulvio Savoiano (pseudónimo de Giacomo Castellani), Avviso di Parnaso, 1619, fol. 16 y Levi, 1899, pp. 23-24n.

11. Crosby, 1958a, pp. 11-12; Jauralde, 1998, p. 370 y Martinengo, 2007, pp. 110-114.

12. Martinengo, 2007, p. 112. 
Evidentemente, la difusión del lugar común de la entrega del autor a las artes mágicas, su extrema fidelidad a Osuna, la consiguiente animadversión hacia la Serenísima que se filtra en muchas de sus obras han contribuido a crear a su alrededor un halo de misterio y de sospecha que ha originado la imagen, ya legendaria, de un Quevedo huyendo de Venecia disfrazado de mendigo y hablando italiano: imagen, esta, recogida, comentada y engrandecida -según escribe Jauralde ${ }^{13}$ - por Tarsia y gran parte de los biógrafos posteriores, comenzando por Astrana ${ }^{14}$. Será solamente a partir de las investigaciones de Beladiez y Crosby ${ }^{15}$ cuando se empiece a poner en duda sea la autenticidad de este episodio sea la visión de un Quevedo como conjurado, hasta que todo se compruebe definitivamente, como veremos, gracias al descubrimiento de documentos originales que demuestran que al tiempo del supuesto complot nuestro autor no podía encontrarse en Venecia.

Sea como fuere, el alboroto provocado por el controvertido suceso de la conjura antiveneciana consigue mellar poco a poco, según sostiene la crítica ${ }^{16}$, la reputación y el prestigio de nuestro autor y de su protector Osuna, ocasionando un paulatino pero inexorable proceso de desestimación destinado a arrastrar a ambos hacia el amargo fin de su experiencia en Italia.

El objetivo de esbozar un perfil, lo más posible fidedigno, de la actuación de Quevedo en Italia nos impone ahora, tras este somero repaso de la principal bibliografía inherente al asunto, ofrecer una reconstrucción esencial de los hechos históricos más relevantes relacionados con tal experiencia. Pasaremos luego a recapitular los hitos de la estancia de don Francisco en las dos cortes virreinales y, finalmente, nos centraremos en las obras del mismo en calidad de testimonios, más o menos directos, de sus actuaciones en el contexto indicado.

\section{ENTORNO HISTÓRICO}

En este apartado nos referimos únicamente al contexto histórico de los dos virreinatos de Osuna, cuyos principales acontecimientos se reducen esencialmente a la guerra por la sucesión del Monferrato y al controvertido episodio de la conjuración de Venecia. Veámoslos.

En abril de 1610, poco antes de su asesinato, Enrique IV de Francia firma el tratado de Bruzolo con el duque Carlos Manuel de Saboya ${ }^{17}$. $\mathrm{Al}$ duque -quien se comprometía en llevar a cabo una guerra contra la Lombardía española y en la cesión de Saboya a la Francia- se le prome-

13. Jauralde, 1998, p. 379.

14. Astrana Marín, 1945 , pp. 265-277.

15. Ver Beladiez, 1954 y Crosby, 1955, 1958b, 2005.

16. Ver, por ejemplo, Jauralde, 1998, p. 385 y Roncero, 1991, p. 39.

17. El tratado tendría que ser el punto de partida de una alianza antiespañola y antihabsbúrgica en defensa de las ciudades italianas; según los planes de Enrico IV, este pacto, que al final nunca se realizó, habría debido incluir también la república de Venecia y el estado pontificio (Cozzi-Knapton-Scarabello, 1992, p. 94). 
te el Monferrato (hasta entonces perteneciente a la familia Gonzaga), la Lombardía misma y el título de rey.

La muerte repentina de Enrique IV y el consiguiente cambio político llevado a cabo por Richelieu (que quería que se aflojaran las tensiones con España) disipan las veleidades espansionistas del duque. Sin embargo, este no se da por vencido y en 1612, a la muerte sin herederos de Francisco IV Gonzaga, reivindica los derechos de sucesión de su nieta Luisa ${ }^{18}$ contra las pretensiones del cardenal Ferdinando, hermano del difunto.

La república de Venecia, implicada indirectamente en la cuestión del Monferrato por su estrecha amistad con Carlos Manuel y por la contigüidad de sus posesiones con los territorios disputados, no se atreve a tomar la defensa del tortuoso duque, a la espera de poder ponderar la posición que más le conviene y por temer una expedición militar de España en el ducado de Mantua. Además, aunque el duque de Saboya es el único príncipe italiano con quien puede contar para llevar adelante su política antiespañola, Venecia conoce muy bien su imprevisibilidad y su tendencia a anteponer sus propios intereses a cualquier otro. Opta por tanto por la vía de la prudencia, dando su apoyo a Ferdinando y causando la reacción indignada de Carlos Manuel; solo gracias a unas intensas maniobras diplomáticas se conseguirá la reconciliación entre los dos estados amigos. Y es así cómo en 1615, al declarar Ferdinando la guerra a la república de Venecia ${ }^{19}$, esta abandona la neutralidad que le había solicitado el embajador español Alonso de la Cueva, marqués de Bedmar, y se alinea con el Piamonte, contra los españoles.

La paz de Madrid de 1617 pone fin a ambas guerras, ratificando, en primer lugar, la renuncia al Monferrato por parte del duque de Saboya, en segundo lugar, el compromiso del archiduque Ferdinando de respetar el concordato de Viena de $1612^{20} \mathrm{y}$, finalmente, la obligación del virrey Osuna de restituir a Venecia los bajeles que le había secuestrado.

Sin embargo, a pesar del recién firmado tratado de Madrid, los representantes españoles en Italia y, en particular, el obcecado triunvirato formado por el duque de Osuna, el marqués de Bedmar y el gobernador de Milán, don Pedro de Toledo, no abandonan su agresividad hacia la Serenísima, de la que deploran el oportunismo ostentado en ocasión

18. Objetivo del duque de Saboya era conseguir la regencia del Monferrato como abuelo de María, hija de Francisco Gonzaga y Margarita de Saboya (ver Cozzi-KnaptonScarabello, 1992, pp. 97-99 y Martinengo, 2015b, pp. 37-38; ver también Linde, 2005, pp. 112-114).

19. Se trata de la «guerra de los uscoques» o «de Gradisca», así llamada por el asalto de los venecianos a la fortaleza de Gradisca, "punto nodale del sistema offensivo e difensivo austriaco» (Cozzi-Knapton-Scarabello, 1992, pp. 99-100); según observa Ruspoli, 2011, p. 149: «Este ataque se justificaba por los venecianos como represalia por la protección del archiduque a los piratas uscoques, asentados en la costa croata del Adriático, en torno al puerto de Segna, que era su principal refugiom. Sobre la cuestión de los uscoques en Quevedo ver Nider, 2009 y 2013.

20. Sobre el pacto de Viena, ver Pérez Bustamante, 1953, pp. 67-68. 
de las últimas dos guerras ${ }^{21}$. Y mientras que en Madrid se invoca la paz a toda costa, en Italia se arman galeones para lanzarse en un nuevo conflicto naval en el mar Adriático; he aquí que se abre la página enigmática de la llamada «conjuración de Bedmar».

Según refiere Giorgio Spini ${ }^{22}$, el dudoso asunto de la conspiración antiveneciana causó la división de los historiadores en dos bandos opuestos que nunca lograron encontrar un acuerdo. Los partidarios de un golpe español (a partir de Battista Nani, en su Historia della Repubblica Veneta de 1662), urdido por el trío Osuna-Bedmar-Toledo, se oponen a los defensores de una escandalosa maquinación diplomática ${ }^{23}$, interna a la propia república y cuya finalidad era desestabilizar el poder español en el norte de Italia y también expulsar al embajador Bedmar de Venecia y desprestigiar al virrey de Nápoles y al gobernador de Milán ante la corte madrileña. La falta de declaraciones oficiales tanto por parte de Venecia como de Madrid sería la causa, según García de Dini ${ }^{24}$, de tal discordancia de opiniones acerca de los autores del complot.

Pero veamos los hechos. Como cada año, en el mes de mayo de 1618 la república de Venecia se apresta para los festejos del día de la Ascensión (aquel año el día 24), en el que se celebra el ritual simbólico de la unión matrimonial de la república con el mar. En aquel momento, sin embargo, la atmósfera en Venecia no se presenta como muy apropiada para festejar: el deterioro debido a los recientes conflictos y la amenazadora presión armada de la flota de Osuna en el mar Adriático

21. El oportunismo de Venecia está bien representado en la imagen que de ella ofrece Quevedo en su Sátira contra los venecianos: "República ramera, que toda la vida está ganando con su cuerpo para valientes que la defiendan. Una vez da su dinero a Francia, otras a Saboya, otras al Conde Mauricio, porque ella más fía en sus trampas que en sus manos» (Roncero, 1984, p. 364; cursiva del autor). Luis Vélez de Guevara también destaca el oportunismo de Venecia: «Fui a Venecia, por ver una población tan prodigiosa, que está fundada en el mar, y [...] que, como la tiene en peso el piélago Mediterráneo, se vuelve a cualquier viento que le sopla» (Vélez de Guevara, El diablo cojuelo, p. 90). En la deformación grotesca del mito de perfección de la Serenísima estudiada hace muchos años por García de Dini (1973) en el ámbito de la literatura del Siglo de Oro, se denuncia la naturaleza camaleónica de Venecia y su tendencia a la hipocresía, reflejada en su posición geográfica anfibia. Tal característica se revela, según observa Martinengo (1972, p. 10; cursiva del autor), en la «agudeza por proporción o por correspondencia» presente en el Criticón de Baltasar Gracián: «aquel murciélago de ciudades, anfibia corte, que ni bien está en el mar ni bien en tierra y siempre a dos vertientes. -iOh, qué política! -exclamó Argos-, qué tan de sus principios le viene, tan fundamentalmente comienza. Y deste su raro modo de estar celebraba el bravo Duque de Osuna la razón de su estado. Aquélla es la nombrada canal con que el mismo mar saben traer acanalado a su con Venecia» (Gracián, Criticón, p. 315).

22. Spini, 1950. Sobre el clamor suscitado por el supuesto complot y el inmediato contraponerse de los comentaristas contemporáneos en dos bandos opuestos, Spini remite a los Comentarios del desengañado, o sea vida de don Diego Duque de Estrada, que reproduce en versión no integral en apéndice (pp. 172-174). Spini saca el texto del Memorial histórico español (pp. 186 y ss.), donde lo había publicado Pascual de Gayangos; para una edición más reciente de los Comentarios, ver Comentarios del desengañado de sí mismo, 1982.

23. Jauralde, 1998, p. 379.

24. García de Dini, 1973. 
ensombrecen el humor de los venecianos. Para dificultar más la situación, la mañana del 18 de mayo, en la plaza de San Marco, se descubren los cadáveres de dos franceses recién ajusticiados. Pocos días después, tienen lugar otras ejecuciones, sin que el gobierno ni otras fuentes oficiales declaren las causas. El silencio del Dux, del Consejo de los Diez y del escritor Paolo Sarpi -líder del partido antiespañol ${ }^{25}$ - acerca de lo sucedido persuade rápidamente a la opinión pública de que se ha acabado de desbaratarse una conjura dirigida a la subversión de la Serenísima. Los ajusticiamientos castigarían a los autores materiales de una conspiración cuyos auténticos artífices serían, en realidad, los tres mayores responsables de la política española en Italia: Bedmar, Osuna y Toledo. Más específicamente, se considera a Bedmar la mente del complot; de aquí el nombre con el que se suele indicar la conjuración.

Aunque no haya certezas acerca de la conjura, muchos son los elementos que van a corroborar las acusaciones de los venecianos contra los ministros españoles. A raíz de las crisis del Monferrato y de los uscoques $\mathrm{y}$, especialmente, de las campañas navales cada vez más apremiantes de don Pedro Girón en el Adriático, las relaciones entre España y la República sufren un considerable deterioro: Venecia tiene conciencia de que la actitud pacífica de Madrid no bastará a reprimir el fanatismo y el antivenecianismo obsesivo de Bedmar y Osuna. Estos, de hecho, exasperados por verse obligados por la corte madrileña a mantener, en las provincias italianas, un status quo pernicioso, según ellos, para la corona misma (pero, sobre todo, incompatible con sus designios bélicos), se inclinan cada vez más a emprender una guerra contra Venecia para punir de una vez su inquina a España. Al no poder actuar manifiestamente, a causa del tratado de paz que Madrid ha estipulado con Venecia, convierten la corte de Nápoles y la embajada de Venecia en auténticos centros de espionaje antiveneciano. Sin embargo, los traiciona su temperamento colérico e impulsivo, tanto en la acción como en las palabras, acrecentando las preocupaciones de Venecia y de sus habitantes. Se temen las peligrosas, además de imprudentes, relaciones de amistad de Alonso de la Cueva con personajes de mala fama como Angelo Badoer, espía y traidor de la República, y Jacques Pierre, ambiguo aventurero francés ${ }^{26}$; y también, las alarmantes e incautas manifestaciones verbales del duque de Osuna, que el residente veneciano en Nápoles, Gasparo Spinelli, refiere en sus informes al Consejo de los Diez y del que cito un pasaje:

25. A finales del siglo XVI, al reaccionario partido de los «Vecchi» - fieles a la España católica y estrechamente vinculados a la curia romana- se contrapuso una nueva clase dirigente -los «Giovani»-, partidaria de una política exterior más dinámica y desaprensiva y una línea anticurial, pero sobre todo antiespañola en política interior (ver Preto, 1975, pp. 95 y ss.). p. 32 .

26. Para más noticias sobre Badoer y Pierre, ver Preto, 1975, pp. 79-82 y Spini, 1948, 
Voglio mandar via questi Vasselli contro Venetia al dispetto del mondo, al dispetto del Re, et al dispetto di Dio, voglio io levarle [a Venezia] la navigazione, et questa giurisditione del Golfo, so che la coglierò alla sprovvista, son io che comando in questo regno, et non altri ${ }^{27}$.

Pero, a pesar de que los venecianos tenían suficientes motivos tanto para suponer una conjura por parte de los ministros españoles como para contraponer un falso complot para desacreditar tales maquinaciones, no disponemos de pruebas concretas que avalen ninguna de las dos hipótesis. La única evidencia que tenemos es que este episodio oscuro de la historia les costó a los tres mayores ministros españoles en Italia la conclusión de sus carreras político-diplomáticas: inmediatamente después de la supuesta conspiración, Bedmar es destituido de su cargo y obligado a irse de Venecia, mientras que Osuna y don Pedro de Toledo desaparecerán del escenario político italiano dos años después. Además, el episodio recordado, junto con los demás acontecimientos históricos que venimos trazando, contribuye a abrir en la opinión de la Italia española aquellas grietas destinadas a ampliarse y penetrar más profundamente tan pronto como los príncipes italianos consigan adherirse a la oposición antihabsbúrgica de los más fuertes países de Europa $^{28}$. La aumentada intolerancia hacia la dominación extranjera ocasiona en la península todo un hervor antiespañol polarizado en la exaltación bien del duque de Saboya bien de la república de Venecia; y esto no a manera de preludio del rescate nacional del siglo xIX (como ha supuesto cierta crítica de principios del siglo xx), sino en la óptica de una polémica contingente contra los dominadores ${ }^{29}$.

\section{La estancia en Italia}

La aventura italiana de Quevedo empieza en 1613, al dejar a España para reunirse, en Sicilia, con don Pedro Girón, su amigo y protector, además de virrey de la isla por entonces. Palermo acoge a Quevedo con mucho entusiasmo por considerarlo el restaurador del prestigio cultural de la corte siciliana. De hecho, como ya hemos dicho, don Francisco,

27. Levi, 1899, p. 23 y n. Tales proyectos, amenazadores y pugnaces, son confirmados en la biografía que de don Pedro Girón escribió Gregorio Leti (Vita di Don Pedro Girón); del mismo ver también Il Governo del duca d'Ossuna.

28. La ocasión llegará con la inminente guerra de los Treinta Años que causará el colapso definitivo de la hegemonía hispánica en Italia.

29. Anatra (1997, p. 159) reconoce en este creciente espíritu antiespañol el origen de una leyenda negra española en versión italiana: «Con la diretta e sempre più stretta implicazione degli aragonesi nella politica italiana, chiamati in Sicilia a fine XIII, insignoritisi della Sardegna agli inizi del xIv e adottati a Napoli un secolo più tardi, con la più diffusa e consistente [...] presenza di uomini di cultura, di commercio e di armi, prendono a circolare, con particolare insistenza tra gli intellettuali italiani, giudizi spregiativi sugli spagnoli. E probabile che qui affondino le radici della leggenda nera spagnola, qui si esprimano i primi segni tangibili di deformazione consapevole dell'immagine corrente dei popoli iberici a fine di propaganda e di polemica politica». 
más que como poeta y literato, actuará de confidente y secretario político del virrey: un personaje poliédrico con quien contaba Osuna para defender, ante un Madrid dudoso y propenso a la paz, su política belicosa orientada tanto a la reducción del dominio veneciano en el Adriático como a la restauración del prestigio de la monarquía española en Italia, deteriorado a causa de los recientes acontecimientos políticos ${ }^{30}$.

En cuanto a la actividad cultural de Quevedo en Sicilia, las pocas noticias que tenemos proceden principalmente de la, en parte fantasiosa, biografía de Paolo Tarsia ${ }^{31}$, quien da cuenta de la amistad de nuestro escritor con algunos humanistas sicilianos como Juanetín Doria, arzobispo de Palermo, Mariano Valguarnera y Martín Lafarina de Madrigal ${ }^{32}$.

En el otoño de 1615, al cabo de dos años transcurridos en Palermo, Quevedo regresa a Madrid para entregar al rey el donativo votado por el parlamento siciliano y destinado a financiar las acciones políticas y militares llevadas a cabo por la Corona. Desde Madrid, en 1616, se traslada directamente a Nápoles, tras el nombramiento, más prestigioso, de Osuna a virrey de la ciudad partenopea ${ }^{33}$.

Ya a partir de los primeros meses de su nuevo virreinato, el duque de Osuna acentúa su índole caprichosa y extravagante, pero sobre todo su tendencia a planear diseños belicosos contra Venecia y el duque de Saboya, para los cuales encuentra, como se acaba de ver, también el apoyo inesperado del gobernador de Milán, don Pedro de Toledo ${ }^{34}$. Mientras tanto, Quevedo ve crecer su papel de hombre público: es a él a quien Osuna, en abril de 1617, confía la tarea muy delicada de ir a Roma para sondear la opinión del Pontífice acerca de sus propósitos antivenecianos; propósitos que, sin embargo, no encontrarán el favor de Pablo V, decidido a mantener la paz en Italia. Y es de nuevo don Francisco quien, por orden del propio Osuna, vuelve a Madrid, a finales de mayo del mismo año, para informar sobre la política italiana e inten-

30. Sobre las intenciones de Osuna y los métodos por los cuales conseguirlas, ver Benigno, 1992, pp. 27-65 y Linde, 2005, pp. 125 y ss.

31. Tarsia, Vida de don Francisco de Quevedo y Villegas, p. 77. Para más noticias sobre las amistades intelectuales de Quevedo en Palermo, ver: Juárez, 1990, pp. 20 y ss.; Jauralde, 1998, pp. 309 y ss. y Martinengo, 2007, pp. 108-109.

32. Quevedo cita, con palabras elogiosas, a Lafarina en el comienzo de Marco Bruto "por haber recibido de éste, en regalo, la medalla original con el efigie del prócer romano, "preciosísima por su antigüedad", que el abad [Lafarina] había heredado de sus ilustres antepasados» (Martinengo, 2007, p. 109).

33. Nápoles entonces era el más importante de los territorios italianos pertenecientes a la monarquía española, además de uno de los centros de mayor poder político, cultural y económico de toda la península (Juárez, 1990, p. 49); sobre la historia de Nápoles bajo la dominación española remito a Villari, 2012.

34. El gobernador de Milán, frente al rechazo de Carlos Manuel de Saboya de retirar el acuerdo de Asti, vuelve a abrir las hostilidades favoreciendo las intenciones expansionistas de Osuna; de aquí las inquietudes en las cortes italianas y en la pacifista corte madrileña. En cuanto a Osuna, este, concretamente, pretendía refrenar al duque de Saboya, debilitando a su más poderoso protector: Venecia (Jauralde, 1998, p. 347). 
tar conseguir, así, el permiso de recurrir a las armas para refrenar tanto la insidiosa República adriática como el tortuoso duque de Saboya.

Por lo que atañe a su actividad intelectual, los numerosos documentos que informan acerca de los acontecimientos internos del virreinato no aluden a la participación directa de Quevedo en la vida artística o, más específicamente, literaria napolitana de primeros del siglo XVII, no obstante hubiese llegado a Nápoles como consejero cultural del virrey. Sin embargo, hoy, por fin, es posible afirmar con seguridad que nuestro escritor fue un "académico ocioso», ya que, como he podido comprobar personalmente, su nombre aparece registrado en el elenco de los miembros de la propia Academia publicado en la base de datos Italian Academies, realizada por la British Library ${ }^{35}$. Claro que, como puntualiza Fernández Murga, don Francisco era un tipo de académico bastante particular: más interesado en «trabar conocimiento con los más eminentes ingenios napolitanos» que en asistir a las discusiones que animaban aquel círculo de intelectuales ${ }^{36}$. Además, raramente Quevedo presta su pluma para celebraciones cortesanas, a menos que no estén estrechamente conectadas con la persona de su protector, como es el caso del soneto Vulcano las forjó, tocólas Midas, que compuso con ocasión de haber retratado al duque el pintor Guido Boloñés ${ }^{37}$. Evidentemente, los apremiantes y quizás inesperados compromisos diplomáticos, así como su implicación en los asuntos políticos, le impiden cultivar asiduamente sus intereses culturales.

Mientras tanto, la política antiveneciana de Osuna en el Adriático sigue impertérrita, a pesar de las disposiciones de la corte madrileña, que le imponían retirar los galeones de ese mar y aceptar la paz estipulada con Venecia en 1617. Los diseños políticos del virrey, convertidos casi en obsesión personal, no pueden sino contagiar a Quevedo, dada su gran admiración hacia el duque. De aquí su animosidad contra Venecia, evidente en muchas de sus obras: recuerdo, por ejemplo, la Sátira contra los venecianos, una obrilla que Victoriano Roncero hace remontar justamente a los años 1617-1618.

35. Para el listado de los miembros de la Academia de los Ociosos ver: http://www. bl.uk/catalogues/ItalianAcademies/AcademyFullDisplay.aspx?RecordId=021-000001040 [fecha de consulta: 10 de noviembre de 2015]; no disponiendo de pruebas fiables, Juárez en 1990 negaba la pertenencia de Quevedo a la Academia (1990, pp. 52-53), mientras que Fernández Murga lo sostiene, pero basándose únicamente en las afirmaciones de Benedetto Croce (Fernández Murga, 1996, p. 51, nota 3).

36. Ver Fernández Murga, 1996, p. 51.

37. Ver Jauralde, 1998, p. 340 y Cappelli, 2013, pp. 57-59; Ettinghausen (1972), en cambio, sugiere la posibilidad de que Quevedo, durante su estancia en Italia, escribiese una serie de poemas importantes: me refiero a las silvas contenidas en un manuscrito, en parte autógrafo, conservado en la Biblioteca Nacional de Nápoles (el XIV.E.46) y cuidadosamente analizado por el estudioso inglés. Por su parte, Alessandro Martinengo atribuye al periodo napolitano, además del soneto citado, tan solo dos silvas, tituladas, respectivamente, Lamentación amorosa. Idilio I e Himno a las estrellas (ver Martinengo, 2015b, pp. 40-41). Sobre las silvas quevedianas y su innovación con respecto a la tradición clásica y humanística ver Cacho Casal, 2012. 
Es justo por entonces cuando el nombre de Quevedo empieza a vincularse con la supuesta conjuración de 1618. Según la versión tradicional de los hechos, en la maquinación de este complot a Quevedo le hubiera correspondido la organización de los detalles del proyecto, «y a este fin se habría trasladado a Venecia disfrazado, para conferenciar con el embajador español y dirigir la operación ${ }^{38}$. Pero el complot se descubre enseguida y el gobierno veneciano desencadena una severa persecución contra los extranjeros implicados en él. A Quevedo, siempre según la versión tradicional, le tocó huir de Venecia «disfrazado de mendigo harapiento ${ }^{39}$ y consiguió, al parecer, salvarse gracias a su dominio del dialecto veneciano.

$\mathrm{Al}$ reconstruir el contexto histórico de la estadía italiana de Quevedo ya hemos aludido a las dificultades con que se han enfrentado los historiadores al intentar lograr un punto de acuerdo sobre el alcance del misterioso affaire de 1618, que a duras penas puede definirse como una conjura. En cuanto a la refutación del mito de la presencia de Quevedo en Venecia y su consiguiente participación activa y directa en el complot, contamos con las investigaciones de James O. Crosby, quien, en un artículo de 1955, demuestra de manera irrebatible que en mayo de 1618 don Francisco se encontraba en España debido a la entrega del donativo napolitano al rey. Es más, el hallazgo, por parte del propio Crosby, de un documento firmado por Quevedo y fechado en Madrid, el 31 de mayo de 1618, quita fundamento a la hipótesis según la cual el autor podría haber viajado de Venecia a Madrid en un intervalo de tiempo (18 de mayo, fecha de la revelación del complot / 31 de mayo) demasiado breve para cubrirse con los medios de trasporte de entonces:

He had been in Madrid since the previous summer, and there is no direct evidence of any trip to Italy in the spring of 1618. Had Quevedo participated in the abortive conspiracy, he would have been in Venice at least until May 18, 1618, the date when the Venetians broke up the plot by the public execution of two of the conspirators. In Madrid on May 31, however, Quevedo executed, before the Notary Public Antonio de Lacalle, a power attorney in favour of the Licenciado Quintaner ${ }^{40}$.

A pesar de esto, la supuesta presencia de Quevedo en Venecia en los días de la conspiración se convirtió enseguida en auténtica leyenda, incluso en motivo folclórico, a cuya difusión contribuyó mucho, en aquel momento, el citado libelo antiespañol, Castigo essemplare de' Calunniatori (1618), donde el autor denuncia, si bien indirectamente, la implicación del poeta en el complot ${ }^{41}$. Más tarde, quien más favoreció

38. Pérez Bustamante, 1945, p. 174.

39. Pérez Bustamante, 1945, p. 174.

40. Crosby, 1955, p. 268.

41. Ver Cappelli, 2011, pp. 50-52. 
la cristalización del topos del disfraz fue el biógrafo Paolo Tarsia en su Vida de don Francisco de Quevedo (1663):

Habiendo ido don Francisco a Venecia con Jaque Pierres y otro caballero español genízaro a hacer una diligencia de grande riesgo, tuvo dicha de poderse retirar sin daño de su persona, y en hábito de pobre, todo andrajoso, se escapó de dos hombres que le siguieron para matarle, a los cuales, aunque estuvieron con él, supo encubrirse de tal arte, que no fue conocido, cayendo la desdicha sobre los dos compañeros, que quedaron presos y [...] fueron ajusticiados ${ }^{42}$.

Pocos años después, la alusión al disfraz de Quevedo reaparece en el prólogo a Las tres Musas últimas castellanas (1670), escrito por el sobrino de Quevedo, Pedro Aldrete:

Habiéndosele ofrecido al duque de Osuna el valerse de su persona [de Quevedo] para que fuese a Venecia a tratar algunas cosas acerca de componer las disensiones que aquel reino tenía con venecianos, conociendo que esto cedía en utilidad del bien público, disfrazado, hizo la diligencia, con gran trabajo y riesgo de su vida ${ }^{43}$.

Después de haberse quedado el poeta en Madrid por lo menos hasta finales de agosto, periodo al que se remontan también sus últimas cartas desde la corte ${ }^{44}$, como hemos visto, regresa directamente a Nápoles donde, según refiere Tarsia, la nobleza y el pueblo partenopeo le acogieran como un triunfador, tributándole honores conforme a su papel de íntimo colaborador del virrey:

El conde Julio César Estela y Miguel Kelkero, con la ocasión de haber vuelto don Francisco de España [...], después de muchos peligros de mar, y tierra, festejándole con la lira de sus odas, artificiosamente templada, dicen, que en su sabiduría, y prudencia descansan las Musas, y el Hércules de su tiempo, el Duque de Osuna ${ }^{45}$.

Se trata, por supuesto, de redundantes tópicos cortesanos finalizados a halagar a un personaje que, no obstante sus importantes compromisos político-diplomáticos y su exigua participación en la vida cultural de la ciudad, actuó como un auténtico mecenas al ofrecer su apoyo y

42. Tarsia, Vida, p. 89.

43. Quevedo, Obra poética, I, pp. 144-145. Los acontecimientos políticos de ese periodo se convertirán en materia novelesca en autores más tardíos; entre ellos recuerdo a Fernández y González que, en pleno siglo xix, escribe Amores y estocadas. Vida turbulenta de Francisco de Quevedo, más reciénmente a Alejandro Casona, con su El caballero de las espuelas de oro, obra teatral sobre la vida aventurosa de Quevedo, y finalmente a Arturo Pérez Reverte, con su novela histórica de espionaje El puente de los asesinos.

44. Crosby, 1958b.

45. Tarsia, Vida, p. 76 y p. 25. Giulio Cesare Stella era un noble romano y Michaël Kelker un humanista alemán. 
protección a escritores, poetas y artistas en general; de esta manera fue creándose un ambiente cultural propicio a la difusión de su fama incluso en toda la península.

Desgraciadamente, la gloria de esos días no iba a durar mucho, ya que el voluble virrey decidiría, al cabo de poco tiempo, sustituir a su fiel colaborador con Luis de Córdoba, muy probablemente por considerar, como sugiere Jauralde ${ }^{46}$, que por entonces «Quevedo se había "gastado" como agente». Antes de finales de 1618, nada menos, don Francisco desaparece definitivamente del escenario político napolitano. No basta; dos años después de la vuelta del poeta, el propio duque de Osuna es destituido de su cargo y obligado a volver a España, donde el nuevo gobierno de Olivares le somete a proceso y le aprisiona ${ }^{47}$. Quevedo, tras haber conseguido disculparse de las acusaciones de complicidad en los atrevidos diseños de su ex-patrón, intentará un lento acercamiento al nuevo grupo de poder, aprovechándose sobre todo de su pluma.

\section{El testimonio de las obras}

La condición privilegiada de nuestro escritor como testigo directo, si no incluso protagonista, de los hechos históricos relacionados con la dominación española en Italia (y, más en general, con la política nacional y europea del tiempo) hace que su producción centrada en la cuestión italiana se convierta en el documento fiable de un comentarista más que autorizado. Dentro del corpus que la compone, sin embargo, es oportuno hacer una clara distinción entre el testimonio, 'en directo', representado por el epistolario - $y$, en modo particular, la porción de la correspondencia mantenida con Osuna ${ }^{48}-$ y el otro, 'en diferido', constituido por los escritos políticos de tema italiano, compuestos después de la muerte del duque, en el periodo de sus turbulentos avatares bajo Felipe IV; esto es: Carta del rey don Fernando el Católico, Mundo caduco, Grandes anales de quince días y Lince de Italia. Dejamos deliberadamente de lado La hora de todos, porque, a pesar de reflejar en parte las mismas preocupaciones políticas expuestas en las obras ahora mentadas, costituye -en palabras de Lía Schwartz ${ }^{49}$ - su “versión literaria» y se caracteriza por una menor referencialidad y cun status imaginario-ficcional»;

46. Jauralde, 1998, p. 390.

47. Para un análisis de las razones que llevaron a la caída en desgracia de Osuna, ver Benigno, 1992, pp. 37-65 y Linde, 2005, pp. 212-258.

48. Se trata de trece cartas en total: once recogidas por Astrana (Quevedo, Epistolario completo), de las que siete fueron redactadas entre noviembre de 1615 y junio de 1616 o sea al tiempo en que Osuna era virrey de Sicilia (son las X, XII, XIII, XVI, XVIII, XIX y XXI) y cuatro entre octubre de 1617 y junio de 1618, siendo el mismo virrey de Nápoles (son las XL, XLIX, L, LIV); a estas hay que añadir, como señala Ettinghausen (2006, p. 74, nota 7), la que publicó Jauralde en 1990 y otra dirigida al secretario de Osuna, Aparicio de Orive, con fecha del 20 de agosto de 1618. Sobre la correspondencia mantenida por Quevedo durante los dos virreinatos ver Jauralde, 1998, pp. 318-332 y pp. 333-395.

49. Schwartz, 1982, p. 954; sobre el tema italiano en las obras de Quevedo, ver también Ceribelli, 2014. 
lo cual hace que añada poco a la definición del papel de Quevedo en Italia ${ }^{50}$.

En cambio, en la perspectiva de nuestro estudio, la correspondencia de Quevedo en general y la con Osuna en particular es de la mayor importancia, primero, por ser casi el único asidero en un momento de exigua creación literaria y, aún más, por su carácter espontáneo, directo $\mathrm{y}$, sobre todo, falto de cualquier filtro debido a la sedimentación temporal de los hechos o a razonados mecanismos retóricos achacables al intento de congraciarse con el nuevo grupo en el gobierno. Lo que, ocurre exactamente con los demás textos que forman parte del corpus.

En las trece cartas dirigidas a Osuna y redactadas entre 1615 y 1618 Quevedo da esencialmente cuenta a su protector de unas cuantas misiones cumplidas en su nombre en la corte madrileña. Dejando aparte las misivas centradas en la relación de eventos cortesanos de cierto alcance y en la descripción de la propia corte, incluso con tono satírico-burles$\mathrm{co}^{51}$, nos interesa destacar aquellas, de tenor serio, que versan sobre los negocios gestionados por don Francisco en calidad de agente del duque. Para seguir el hilo de sus actividades y tener de ellas un cuadro completo, hay que tener en cuenta, además, las cartas publicadas en el Epistolario editado por Astrana, pero que no siempre son obra de nuestro autor; me refiero a las cartas dirigidas por don Pedro Girón al rey Felipe III y viceversa, a las intercambiadas entre el propio rey y Quevedo y, finalmente, a las que este escribió al Parlamento napolitano ${ }^{52}$.

Como se lee en el Diccionario de Autoridades, el agente es «el que solicita diligencia y procura los negocios de otro ${ }^{53}$ y, de hecho, según se desprende del conjunto de las citadas misivas, Quevedo en la corte no hace sino actuar con poder de Osuna, sobre todo en asuntos de tipo económico. Se trata, en muchos casos, de operaciones de cierta oficialidad, como presentarle al monarca el balance de la real hacienda o entregarle las dádivas virreinales ${ }^{54}$, o bien cobrar deudas o descubrir hasta fraudes en perjuicio del «real patrimonio ${ }^{55}$. Bastaría esto para demostrar el grado de confianza que el virrey debía de tener en su brazo

50. Omitimos también referirnos a los poemas conectados con la experiencia del autor en Italia por tratarse principalmente de composiciones encomiásticas, en gran parte destinadas a la exaltación del duque de Osuna, a las que hemos ya dedicado un artículo; ver Cappelli, 2013.

51. Para un puntual análisis de las cinco cartas del conjunto marcadas por una fuerte huella satírica, ver Ettinghausen, 2011.

52. De hecho, Quevedo, en algunos casos, ejecuta comisiones que le encomienda directamente el Parlamento de Nápoles, con cuyos diputados intercambia cartas: de su parte, para comunicar el feliz éxito de la misión y, de parte de ellos, para alabarle por su diligencia y exhortarle a continuar en sus oficios (ver, por ejemplo, las cartas Xxxv, xxxIX y XLI, Epistolario completo, p. 61, p. 69 y p. 72, respectivamente; sobre el tema ver Pérez Bustamante, 1933).

53. Aut, s.v. «agente».

54. Ver, respectivamente, las cartas XxxI y xxxIV, entre Osuna y el rey (Epistolario completo, pp. 60-61).

55. Ver carta XXXıII (Epistolario completo, p. 60). 
derecho al encomendarle cargos tan delicados; sin considerar, además, que el propio duque llega a suplicar al monarca para que autorice a Quevedo a volver a Nápoles, al no tener sujeto igualmente fiable para el tratamiento de cruciales cuestiones monetarias:

Suplico a vuestra majestad mande que con toda brevedad se despache don Francisco de Quevedo, pues hasta su vuelta, lo más que puedo hacer es ir suspendiendo estos negocios, por la falta que tengo de personas de quien fiallos ${ }^{56}$.

Pero, de verdad, no existe tan solo el plan oficial en la actuación de nuestro autor en la corte, ya que en las cartas constan también algunos ejemplos de tratos más bien particulares; esto es: dar cuenta a Osuna de los gastos realizados ${ }^{57}$, pero principalmente corromper a cortesanos de peso con regalos ${ }^{58}$ y sobornos, una tarea, esta, que se podía confiar solo al más íntimo consejero, dado su carácter evidentemente ilegítimo.

Resulta, pues, que don Francisco, en sus misiones a la corte, actúa en dos niveles distintos: uno legal, casi en calidad de secretario de hacienda o emisario de los parlamentos virreinales, y otro decididamente ilegal, como hombre de confianza del duque, impulsando cohechos en las altas esferas, primero, con el fin de favorecer el nombramiento de Osuna a virrey de Nápoles y, después, con el de asegurarse un respaldo para la política atrevida y beligerante del mismo. A este propósito, si pensamos con Ettinghausen ${ }^{59}$ en la «severa moral» neoestoica de que Quevedo suele hacerse portavoz, sorprende mucho y hasta perturba un poco la desenvoltura con la que, en la carta XII, por ejemplo, refiere a su corresponsal, con tono entre irónico y cínico, de qué manera consigue tener media corte en su puño tan solo con hacer husmear un soborno de treinta mil ducados que, al final, nunca concederá. Escribe Quevedo en la carta citada ${ }^{60}$ : «A todos los tengo con esperanzas: hágoles gestos de dádivas; hablo palabras con barriga, preñadas; y sospecho que, si V. Ex. ${ }^{a}$ me envió treinta mil, le he de volver treinta mil y tantos», y después añade: «juro a Dios que, con solo amagarles con los treinta mil, no me ha de quedar hombre en pie» y, hacia el final de la carta, refiriéndose al dinero mismo, concluye: “Gran cosa es, aunque no se dé, saber que lo hay». Pero hay más: el desenfado y la confianza que suponen tanto la relación como el intercambio epistolar entre nuestro escritor y el duque

56. Carta $\mathrm{xxx}$ (Epistolario completo, p. 54).

57. Ver, para ambos, la carta XL (Epistolario completo, pp. 69-71).

58. Piénsese, por ejemplo, en la carta XI, en que Osuna sugiere a Quevedo que ofrezca al secretario del duque de Uceda, Salazar, además de una sortija de quinientos ducados, "una cadena de otros quinientos», o en la carta L, del 14 de marzo de 1618, donde Quevedo refiere al virrey los caprichos del duque de Uceda al pretender que se le entregaran muy de prisa los regalos que Osuna le había destinado (ver Epistolario completo, respectivamente, p. 27 y pp. 85-86).

59. Ettinghausen, 2011, p. 18.

60. Epistolario completo, p. 29; para las restantes citas de la misma carta, ver p. 30. 
llevan al primero incluso a vanagloriarse del poder y la autoridad que el dinero le concede como agente del otro, sin pensar en lo arriesgado y comprometedor de ese modo de actuar; así que le escribe: «Ándase tras mí media corte, y no hay hombre que no me haga mil ofrecimientos en el servicio de V. Ex. ${ }^{a}$, que aquí los más hombres se han vuelto putas, que no las alcanza quien no da», para terminar la misiva proclamando: «Juro a Dios que parece que hay jubileo en mi casa, según la gente entra y sale: más séquito tengo yo que un consejo entero, y hame sido de grande autoridad y reputación el negociar».

A pesar de que el principal asunto de la estancia de don Francisco en la corte consiste, como acabamos de ver, en cuestiones esencialmente económicas, sean estas comisiones oficiales o maniobras cortesanas, se perfila también, sobre todo tras las últimas, un tipo de acción más bien político-diplomática. Especialmente en los años napolitanos, Quevedo, a través de maquinaciones y sobornos, mueve los hilos de la corte en calidad de favorecedor y defensor de la política, cada vez más ambiciosa, del duque, buscando consensos y protección como, para decirlo en palabras de Ettinghausen, «un habilísimo spin doctor, un portavoz o comentarista semioficial que pinta los hechos con los colores que más pueden favorecer la línea política seguida por su amo» ${ }^{61}$. De sus maniobras, como ya hemos visto, da cuenta en sus misivas a Osuna, donde también comenta las reacciones de los personajes sobornados o revela indiscreciones de palacio; pero el cargo de nuestro autor prevé también que informe directamente al monarca acerca de los asuntos napolitanos, exaltando al virrey y sus éxitos bélicos para ganarle total libertad de actuación. Es el caso, por ejemplo, de la carta XLII ${ }^{62}$ a Felipe III, donde, tras describir con abundancia de detalles los triunfos militares de Osuna en el Adriático y en Lombardía y poner de relieve su efecto positivo para la gloria de la monarquía y la «reputación de sus armas y vasallos», pasa Quevedo a enumerar, uno tras otro, los principales méritos de don Pedro Girón:

Haber desencantado las quimeras de Venecia y los miedos y fantasmas que con ella ponía Italia [...].

Haber hecho un acto tan solemne contra la posesión que alegan del golfo, en perjuicio de la marina de vuestra majestad y otros príncipes.

Haber hecho ver al mundo que el desorden de un vasallo de vuestra majestad, virrey de Nápoles, ha hecho con efecto lo que desde los ginoveses acá no ha habido monarca que lo haya osado pensar a solas.

Haber el duque de Osuna hecho confesar por fuerza a los venecianos que contra él no pueden nada [...].

Haberlos reducido a estado que, pidiendo (como lo han hecho) favor y ayuda al turco, hayan ignominiosamente confesádole a él y a todo el mundo su flaqueza $[\ldots]$.

61. Ettinghausen, 1995, pp. 242-243.

62. Epistolario completo, pp. 73-75. 
Haber mostrado a los príncipes, que desde los motivos [sic.] de Enrique IV están atentos a la ruina de esta monarquía, no solo que no está impotente como la juzgan, más poderosísima [...].

Haber hecho un millón y más de presas $[\ldots]^{63}$.

La enumeración de los muchos y eminentes éxitos de su protector le permite a Quevedo pasar inmediatamente después a solicitar al monarca un premio para tanta valía, es decir su «licencia» para poder seguir en audaces empresas “con mayores acrecentamientos» ${ }^{64}$. Pero la pretensión pedida choca, evidentemente, con la política pacifista mantenida por la corte madrileña, cuyos inconvenientes Quevedo ilustra al rey, sin ningún reparo, en la parte final de la carta, al comentar la noticia de la retirada del mar Adriático de las escuadras y galeones de Nápoles y Sicilia. Para evidenciar las desventajas de tal estrategia y contraponerlas a los méritos bélicos de Osuna, don Francisco acude de nuevo a la forma del listado y al mismo estilo conciso, esta vez, registrando, uno por uno, todos los efectos nefastos que parecidas resoluciones pueden comportar. Entre ellas recuerdo el «Haber con esta retirada de galeones y salida de las escuadras, dejado lugar a los venecianos de repararse con el comercio» o el «Haber malogrado acción tan gloriosa como se había empezado» o, también, “Haber mostrado demasiado cuidado y recelo de la armada del Turco» ${ }^{65}$. Y concluye, dando muestra de su profundo conocimiento de la situación del Adriático explicando, primero, lo innecesario de tal retirada e insistiendo, en segundo lugar, en las posibles consecuencias negativas para la reputación de la corona española $y$, finalmente, remachando que el único remedio posible es permitir que el duque de Osuna obre con libertad en el mar Adriático y continúe su política expansiva.

Durante el virreinato napolitano, pues, la tarea de Quevedo al servicio del duque se especializa cada vez más en el terreno de lo político y lo militar ${ }^{66}$, hasta llegar al periodo más complejo y conflictivo de su carrera de hombre público, que coincide con la llamada conjura de Venecia. De esto también nuestro autor ha dejado rastro en sus cartas. Pero ahora no se trata ya de promover ni simplemente defender la causa política de Osuna, sino de exhibir explicaciones e, incluso, justificar la actuación de este ante la corte, informando detalladamente acerca de la sucesión de los hechos que han llevado al supuesto complot. Las misivas a que me refiero son, esencialmente, dos informes sobre la cuestión veneciana dirigidos por Quevedo al rey Felipe III y al Consejo de

63. Epistolario completo, p. 74.

64. Epistolario completo, p. 74.

65. Epistolario completo, p. 74.

66. Recordemos, a este propósito, que aparte de las cartas, Osuna encarga a nuestro autor defender personalmente su actuación político-militar ante el Papa y el rey; según Jauralde, se podría afirmar incluso que Quevedo se convierte, en esos años, en «auténtico "ministro de la guerra", preparando una campaña en toda Europa" (Jauralde, 1998, p. 344 y p. 353 ). 
Estado en la primavera de $1618^{67}$, más o menos un mes después del descubrimiento de la conspiración; allí el escritor presenta lo sucedido explicando la conducta política y militar del duque e insistiendo en su caballerosidad, al combatir con galeones y galeras y no con embrollos y traiciones como hacen los venecianos:

De esta suerte empezaron sus estratagemas venecianos de que el Duque de Osuna hizo poca cuenta, sospechando semejante modo de guerrear. [...] de manera que hasta ahora lo que es cierto es que la bajeza de los medios con que han querido ejecutar la mala intención está de su parte, no habiendo tenido el Duque de Osuna necesidad para romperlos de otro medio que los galeones y galeras con que lo ha hecho ${ }^{68}$.

Ambas memorias demuestran no solo su perfecto conocimiento de los hechos a que se refiere, sino también su total fidelidad a Osuna - como atestiguan también las últimas dos cartas al duque ${ }^{69}$ - y la perfecta identificación entre los dos, «hasta el punto que a veces» parece que Quevedo está “exponiendo sus ideas atribuyéndolas al virrey» ${ }^{70}$. Como destaca Ettinghausen, estos informes, junto con otros dos de tono parecido escritos en el mismo periodo o poco antes ${ }^{71}$, «se anticipan a sus obras políticas posteriores» ${ }^{72}$, dado su carácter apologético. Sin embargo, como ya hemos subrayado, al escribir sus memoriales históricos siendo ya acusado de complicidad en los diseños políticos del duque, Quevedo abordará las distintas cuestiones relativas a la situación italiana con mayor cautela, siendo su objetivo ya no solo el de justificar la política de su patrón, sino defenderse a sí mismo y aconsejar al nuevo grupo en el poder para congraciárselo. Con esta finalidad exhibe su profundo conocimiento de la situación política del Mediterráneo y acude a su experiencia de hombre de confianza de Osuna. De este modo, por ejemplo, en la Carta del rey don Fernando el Católico al primer virrey de Nápoles (1620), además de volver a defender, esta vez menos explicítamente, la política de Osuna, se preocupa esencialmente de poner en guardia al nuevo equipo gubernamental contra «validos y malos consejeros » ${ }^{73}$; en Mundo caduco (1623), con el propósito de eludir sus responsabilidades en los proyectos de Osuna, ofrece su personal punto de vista sobre algunos acontecimientos cruciales de la presencia española en Italia (entre ellos la delicada cuestión de los uscoques); en

67. Son las cartas LI, según Astrana (entregada en sesión del 25 de junio», y LIII, fechada en 26 de junio (Epistolario completo, pp. 87-89 y pp. 90-92, respectivamente).

68. Epistolario completo, pp. 87-88

69. Son las LIV del 26 de junio de 1618 y la LIX, escrita desde la cárcel de Uclés casi tres años después, el 25 de febrero de 1621 (Epistolario completo, pp. 92-96 y pp. 99-101).

70. Ruspoli, 2011, p. 156.

71. Números XLII y XLVI del Epistolario completo (respectivamente, pp. 73-75 y pp. 99-101).

72. Ettinghausen, 1995, p. 242.

73. Peraita, 1998, p. 131 . 
Grandes anales (1623) vuelve al tono apologético de Mundo caduco, pero acudiendo a otra estrategia autodenfesiva, o sea denunciar la corrupción de ciertos ministros y, finalmente, en Lince de Italia (1628) aconseja al rey Felipe IV que desconfíe de la falsa amistad de Francia y Saboya.

Desde la perspectiva de la definición del papel de don Francisco en Italia, no podemos afirmar que las obras redactadas una vez finalizada su carrera al servicio de Osuna añadan algo nuevo, sino que confirmen, más bien, lo que venimos delineando en estas páginas. En todas ellas nuestro autor emplea su experiencia italiana como crédito y apoyo en respaldar sus opiniones; asimismo, su condición de espectador privilegiado de los sucesos aludidos, además de partícipe de los mismos, le permite sentirse parte integrante de un escogido grupo de expertos políticos autorizados para aconsejar a los gobernantes en calidad de «conocedores de la retórica del poder» y su lenguaje $\mathrm{e}^{74}$. De las cinco obras que acabamos de citar, quizás, sea Lince de Italia la que merezca mayor atención siendo la única en que Quevedo se dedica de manera muy explícita y esclarecedora a definir los servicios prestados a la Monarquía:

Once años me ocupé en el real servicio de vuestro padre (que está en el cielo) en Italia, con asistencia en Sicilia y Nápoles, y noticias y negocios en Roma, Génova y Milán; y esto fue cuando nacía la discordia que hoy dura con señas de vida muy larga.

El ministro que seguí fue don Pedro Girón, Duque de Osuna, y con él fui a cargo de Sicilia y bajé al de Nápoles. Encargome de los parlamentos de los dos reinos, y de todo lo que se ofreció en vuestro real servicio, así con la santidad de Paulo V como con los potentados, y en lo tocante a la restitución del mar Adriático. La calidad de mis servicios, el Duque de Osuna la certificó por su carta a la majestad de vuestro padre; y su Majestad (que está en el cielo) respondió por Consejo de Estado [...].

Esto, Señor, no es ostentarme suficiente para la pretensión, sino acreditarme ejercitado para el advertimiento; y verá Vuestra Majestad que catorce viajes, que por mar y tierra en vuestro servicio, no sin fruto he hecho, han tenido más de estudio aprovechado que de peregrinación vagabunda ${ }^{75}$.

Nada más claro y fiable que las afirmaciones de la parte interesada para ir terminando nuestro estudio en vista de una definición de la actuación de Quevedo en Italia. Del pasaje citado, que el autor inserta en su obra como forma de captatio benevolentiae subrayando «el valor de su experiencia y cargos ${ }^{76}$, se desprende que Quevedo se siente sobre todo acreditado para ejercer de consejero, una función que desempeña a lo largo de todos los años transcurridos en el séquito de Osuna. Quevedo es, de hecho, el hombre de confianza, el brazo derecho de Osuna, a quien este interpela a la hora de tomar decisiones y a quien confía delicados cargos de mayor o menor oficialidad, como hemos visto. Según lo

74. Ver Peraita, 1998, p. 131.

75. Quevedo, Lince de Italia u zahorí español, pp. 68-69.

76. Azaustre Galiana, 2004, p. 53. 
que venimos demostrando, es posible afirmar que el que jugó Quevedo en Italia fue un papel polifacético, fundado esencialmente en la profunda confianza recíproca que sellaba su relación con don Pedro Girón. A diferencia de Lupercio Leonardo de Argensola, de quien consta que cubrió la plaza de Secretario de Estado y Guerra en el gobierno del precedente virrey ${ }^{77}$, Quevedo no recibió ningún nombramiento oficial de entre los previstos por el ceremonial de los virreinatos de entonces ${ }^{78}$, aparte del cargo de embajador que le concedió, primero, el Parlamento siciliano, en agosto de 1615 y, después, el proprio virrey, a comienzos de $1617^{79}$. Más simplemente, como sostiene Jauralde, Francisco de Quevedo "formaba parte de la camarilla privada del duque de Osuna»", de ahí que su actividad fuera el resultado de un acuerdo personal entre los dos. No por eso su tarea fue de menor peso: como demuestra el nefasto epílogo de su aventura italiana, el hecho de haberse convertido en el más íntimo e importante colaborador del virrey, además de su principal agente en toda clase de gestiones y negocios, le comportó muchas y grandes responsabilidades que, a la hora de la caída del duque, le costaron, como era de esperarse, grandes perjuicios y persecuciones. Solo su excelsa calidad de escritor y la enorme experiencia política acumulada en los años italianos le permitirán lenta y difícilmente volver a acercarse a la cumbre del poder.

\section{Bibliografía}

Anatra, Bruno, «La leggenda nera in Italia: Boccalini e Tassoni», Annali della facoltà di Lettere e Filosofia dell'Università di Cagliari, 52, 1997, pp. 159-166.

Astrana Marín, Luis, La vida turbulenta de Quevedo, Madrid, Ed. Gran Capitán, 1945.

Aut, Diccionario de Autoridades, Madrid, Gredos, 1963, 3 vols.

Azaustre Galiana, Antonio, “Estructura y argumentación del Lince de Italia $u$ zahorí español,, La Perinola, 8, 2004, pp. 49-75.

Beladiez, Emilio, Osuna el Grande. El duque de las Empresas, Madrid, Alhambra, 1954.

Benigno, Francesco, L'ombra del re. Ministri e lotta politica nella Spagna del Seicento, Venezia, Marsilio, 1992.

Blanco, Mercedes, «Del Infierno al Parnaso. Escepticismo y sátira política en Quevedo y Trajano Boccalini), La Perinola, 2, 1998, pp. 155-193.

Cacho Casal, Rodrigo, La esfera del ingenio. Las silvas de Quevedo y la tradición europea, Madrid, Biblioteca Nueva, 2012.

Cappelli, Federica, “La República de Venecia...» attribuita a Francisco de Quevedo (1617): il genere degli Avvisi di Parnaso nella controversia politico-letteraria ai tempi della «Congiura di Bedmar» (1618), tesis doctoral, Universidad de Pisa, 2001.

77. Ver Green, 1951, p. 376.

78. Ver De Nardi, 2014.

79. Ver Jauralde, 1998, p. 317 y Ruspoli, 2011, p. 149 y p. 153.

80. Jauralde, 1998, p. 342. 
Cappelli, Federica, «La República de Venecia... (1617) attribuita a Francisco de Quevedo. Saggio di edizione», Rivista di Filologia e Letterature Ispaniche, 6, 2003, pp. 259-274.

Cappelli, Federica, “La Repubblica de Venecia... (1617) y el Castigo essemplare de' Calunniatori (1618): ¿una contienda político-literaria entre Quevedo y Castellani?», La Perinola, 15, 2011, pp. 37-55.

Cappelli, Federica, «Italia en el encomio quevediano al duque de Osuna (con unas reflexiones en torno a las musas Clío y Melpómene)", en Italia en la obra de Quevedo, ed. María José Alonso Veloso y Alfonso Rey, Santiago de Compostela, Universidad de Santiago de Compostela, 2013, pp. 53-70.

Ceribelli, Alessandra, “El tema de Italia en la obra en prosa de Quevedo», en «Sapere Aude». Actas del III Congreso Internacional Jóvenes Investigadores Siglo de Oro (JISo 2013), ed. Carlos Mata Induráin, Adrián J. Sáez y Ana Zúñiga Lacruz, Publicaciones Digitales del GrIso, 2014, pp. 59-69.

Cozzi, Gaetano, Michael Knapton, Giovanni Scarabello, Storia d'Italia. La Repubblica di Venezia nell'età moderna. Dal 1517 alla fine della Repubblica, dir. G. Galasso, Torino, UTEт, 1992, vol. XII, tomo II.

Crosby, James O., "Quevedo's Alleged Participation in the Conspiracy of Venice», Hispanic Review, 23, 1955, pp. 259-273.

Crosby, James O., "Quevedo and the Court of Philip III in 1615: Neglected satyrical Letters and new biographical Data», Publications of the Modern Language Association of America, 71, 1956, pp. 1117-1126.

Crosby, James O., «Noticias y documentos de Quevedo: 1616-1617», Hispanófila, 4, 1958a, pp. 3-22.

Crosby, James O., “Nuevos documentos para la biografía de Quevedo, 16171621 », Boletín de la Biblioteca Menéndez y Pelayo, 34, 1, 1958b, pp. 229-261.

Crosby, James O. (ed.), Nuevas cartas de la última prisión de Quevedo, Woodbridge, Tamesis, 2005.

De Nardi, Loris, Oltre il cerimoniale dei viceré. Le dinamiche istituzionali nella Sicilia barocca, Padova, Libreriauniversitaria.it Edizioni, 2014.

Duque de Estrada, Diego, Comentarios del desengañado de sí mismo. Vida del mismo autor, ed. Henry Ettinghausen, Madrid, Castalia, 1982.

Ettinghausen, Henry, “Un nuevo manuscrito autógrafo de Quevedo», Boletín de la Real Academia Española, 52, 1972, pp. 211-279.

Ettinghausen, Henry, «Ideología intergenérica: la obra circunstancial de Quevedo», en Estudios sobre Quevedo. Quevedo desde Santiago entre dos aniversarios, coord. Santiago Fernández Mosquera, Santiago de Compostela, Universidad de Santiago de Compostela, 1995, pp. 225-259.

Ettinghausen, Henry, “Relación y nuevas y visitas": la primera carta conservada de Quevedo al duque de Osuna», La Perinola, 10, 2006, pp. 73-86.

Ettinghausen, Henry, “"El diablo anda suelto": sátira y burla en las cartas de Quevedo al duque de Osuna», en Estudios sobre Quevedo y la sátira en el siglo XVII, ed. Carlos Vaíllo y Ramón Valdés, Barcelona, PPU, 2011, pp. 1-22.

Fernández Murga, Félix, «Francisco de Quevedo, académico ocioso», en Homenaje a Quevedo, ed. Víctor García de la Concha, Salamanca, Universidad de Salamanca, 1996, pp. 45-52.

Forti, Carla, “Un lascasiano e polemista antispagnolo del Seicento a Venezia: Giacomo Castellani», en Studi in onore di Armando Saitta dai suoi allievi pisani, ed. Regina Pozzi y Adriano Prosperi, Pisa, Giardini, 1989, pp. 73-98.

Fulvio Savoiano, Valerio, Avviso di Parnaso. Nel quale si racconta la povertà e miseria, dove è giunta la Repubblica di Venezia et il Duca di Savoia. Scritto da un 
curioso Novellista Spagnuolo. Con alcune annotazioni molto importanti sopra le cose che in esso si contengono. Per Valerio Fulvio Savoiano. Il tutto tradotto dalla lingua spaguola in questa nostra italiana. Con privilegio. In Antopoli. 1619.

Gagliardi, Donatella, «Bosquejos del duque de Osuna en la literatura parnasiana del xvir (de Boccalini a Castellani)", en Cultura de la guerra e arti della pace. Il III Duca di Osuna in Sicilia e a Napoli (1611-1620), ed. Encarnación

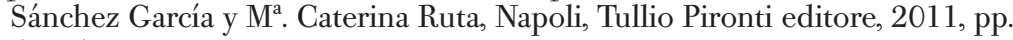
561-576.

García de Dini, Encarnación, «Trayectoria del mito de Venecia en la literatura española de la edad barroca», en Venezia nella letteratura spagnola e altri studi barocchi, Padova, Liviana Editrice, 1973, pp. 29-84.

Gracián, Baltasar, El Criticón, ed. Santos Alonso, Madrid, Cátedra, 1990.

Green, Otis H., «Bartolomé Leonardo de Argensola, Secretario del Conde de Lemos», Bulletin Hispanique, 53, 4, 1951, pp. 375-392.

Hendrix, Harald, Traiano Boccalini tra erudizione e polemica. Ricerche sulla fortuna e bibliografia critica, Firenze, Leo S. Olschki, 1995.

Italian Academies [en línea], London, British Library, [fecha de consulta: 10 de noviembre de 2015], base de datos disponible en: http://www.bl.uk/catalogues/ItalianAcademies/About.aspx.

Jauralde Pou, Pablo, Francisco de Quevedo (1580-1645), Madrid, Castalia, 1998. Juárez, Encarnación, Italia en la vida y en la obra de Quevedo, New York, Peter Lang, 1990.

Leti, Gregorio, Il Governo del duca d'Ossuna nello Stato di Milano, Colonia, Battista della Croce, 1678.

Leti, Gregorio, Vita di don Pedro Girón, duca d'Ossuna, Amsterdam, Gallet, 1699, 3 vols.

Levi, Eugenia, «Per la congiura contro Venezia nel 1618: una relatione di Fra” Paolo Sarpi», Nuovo archivio veneto, 9, 17, parte I, 1899, pp. 5-65.

Linde, Luis M., Don Pedro Girón, duque de Osuna. La hegemonía española en Europa a comienzos del siglo XVII, Madrid, Encuentro, 2005.

López Ruiz, Antonio, «La aventura veneciana de Quevedo», Revista de Literatura, 47, 94, 1985, pp. 167-178.

López Ruiz, Antonio, Tras las huellas de Quevedo (1971-2006), Almería, Editorial Universidad de Almería, 2008.

Marañón, J. Gregorio, “Quevedo y Castellani», Boletín de la Biblioteca Menéndez y Pelayo, 22, enero-marzo, 1, 1946, pp. 356-371.

Martinengo, Alessandro, “Da Boccalini a Gracián: dibattito su Venezia», en Venezia nella letteratura spagnola e altri studi barocchi, Padova, Liviana editrice, 1972, pp. 1-27 (luego publicado en: Homenaje a Fernando Antonio Martínez. Estudios de lingüística, filología e historia cultural, Bogotá, Instituto Caro y Cuervo, 1979, pp. 447-473).

Martinengo, Alessandro, "Quevedo y Venecia (Una versión desconocida de una sátira de don Francisco)", en Actas del quinto Congreso Internacional de Hispanistas (Bordeaux, 2-8 de dicembre de 1974), Bordeaux, Instituto de Estudios Ibéricos e Iberoamericanos, Universidad III, 1977, pp. 633-642.

Martinengo, Alessandro, La astrología en la obra de Quevedo, Madrid, Alhambra, 1983.

Martinengo, Alessandro, "Quevedo, modelo del diplomático tacitista», en Quevedo: fronteras de la filología. Con una mirada hacia Gracián, Pamplona, Eunsa, 2006, pp. 39-47. 
Martinengo, Alessandro, "Quevedo en Italia, inigromante u oculto consejero de príncipes?», en Sobre Quevedo y su época. Homenaje a Jesús Sepúlveda, ed. Felipe B. Pedraza Jiménez y Elena E. Marcello, Cuenca, Ediciones de la Universidad de Castilla-La Mancha, 2007, pp. 107-124.

Martinengo, Alessandro, «Los paisajes italianos de Quevedo (un conceptista de viaje)», en Almargen de Quevedo. Paisajes naturales. Paisajes textuales, New York, IDEA / IGAS, 2015a, pp. 47-64 (antes publicado en: La Perinola, 13, 2009, pp. 263-280).

Martinengo, Alessandro, "Vulcani mitologici, Alpi a lo divino», en Alessandro Martinengo, Al margen de Quevedo. Paisajes naturales. Paisajes textuales, New York, IDEA / IGAS, 2015b, pp. 35-46 (Antes publicado en: Cultura de la guerra e arti della pace. Il III Duca di Osuna in Sicilia e a Napoli (1611-1620), ed. Encarnación Sánchez García y $\mathbf{M}^{\mathrm{a}}$. Caterina Ruta, Napoli, Tullio Pironti, 2011, pp. 589-601).

Mérimée, Ernest, Essai sur la vie et les oeuvres de Francisco de Quevedo (15801645), Paris, Alphonse Picard, 1886.

Nider, Valentina, “Sarpi, Quevedo e la pubblicistica sulla guerra degli Uscocchi», en Giudizi e pregiudizi, ed. Maria Grazia Profeti, Firenze, Alinea, 2009, vol. I, pp. 211-237.

Nider, Valentina, «Quevedo y los uscoques: trasfondo histórico de una secuencia de Mundo caducom, en Italia en la obra de Quevedo, ed. María José Alonso Veloso y Alfonso Rey, Santiago de Compostela, Universidad de Santiago de Compostela, 2013, pp. 123-143.

Olivari, Michele, Avisos, pasquines y rumores. Los comienzos de la opinión pública en la España del siglo XVII, Madrid, Cátedra, 2014.

Peraita, Carmen, Quevedo y el joven Felipe IV. El príncipe cristiano y el arte del consejo, Kassel, Reichenberger, 1997.

Peraita, Carmen, «El arte del consejo: el comentario de Quevedo a la Carta de Fernando el Católicom, en Actas del XII Congreso de la Asociación Internacional de Hispanistas, ed. Jules Whicker, Birmingham, The University of Birmingham, 1998, vol. III, pp. 131-138.

Pérez Bustamante, Ciriaco, «Un parlamento napolitano en 1617. Cartas y noticias de don Francisco de Quevedom, Boletín de la Universidad de Santiago de Compostela, 17, 1, 1933, pp. 375-400.

Pérez Bustamante, Ciriaco, “Quevedo, diplomático», Revista de Estudios Políticos, 13, 1945, pp. 159-183.

Pérez Bustamante, Ciriaco, «El dominio del Adriático y la política española en los comienzos del siglo xvII), Revista de la Universidad de Madrid, 5, II, 1953, pp. 57-80.

Preto, Paolo, Venezia e $i$ Turchi, Firenze, Sansoni, 1975.

Quevedo, Francisco de, Lince de Italia u zahorí español, ed. Ignacio Pérez Ibáñez, Pamplona, Eunsa, 2002.

Quevedo, Francisco de, Obra poética, ed. José Manuel Blecua, Madrid, Castalia, 1969 , vol. I.

Quevedo, Francisco de, Obras completas de Francisco de Quevedo, ed. Aureliano Fernández-Guerra, Madrid, Atlas, 1946-1951, вaE, tomo xLvinI.

Quevedo, Francisco de, Epistolario completo, ed. Luis Astrana Marín, Madrid, Instituto Editorial Reus, 1946.

Quevedo, Francisco de, Obras completas: Obras en verso, ed. Luis Astrana Marín, Madrid, Aguilar, 1932, vol. 2. 
Reglá, Juan, “Un dato para la biografía de Quevedo», en Revista de Filología Española, 40, 1, 4, 1956, pp. 234-235.

Roncero, Victoriano, “Sátira contra los venecianos, de Francisco de Quevedo», El Crotalón, 1, 1984, pp. 359-372.

Roncero, Victoriano, Historia y política en la obra de Quevedo, Madrid, Pliegos, 1991.

Ruspoli, Carlo Emanuele, Retratos. Anécdotas y secretos de los linajes Borja, TéllezGirón, Marescotti y Ruspoli, Madrid, Real Academia Matritense de Heráldica y Genealogía, 2011.

Schwartz, Lía, «Referencialidad del discurso satírico: la Hora de todos de Quevedo», en Actas del VII Congreso de la Asociación Internacional de Hispanistas, ed. Giuseppe Bellini, Roma, Bulzoni, 1982, pp. 953-961.

Spini, Giorgio, «La congiura degli Spagnoli contro Venezia del 1618», Archivio storico italiano, 107, 1949, pp. 17-53.

Spini, Giorgio, «La congiura degli Spagnoli contro Venezia del 1618», Archivio storico italiano, 108, 1950, pp. 159-174.

Tarsia, Paolo, Vida de don Francisco de Quevedo y Villegas, reproducción facsimilar cuidada por M. Prieto Santiago, prólogo de Felipe. B. Pedraza Jiménez, Cuenca, Universidad de Castilla-La Mancha, 1997.

Vélez de Guevara, Luis, El diablo cojuelo, ed. Ramón Valdés, estudio preliminar Blanca Periñán, Barcelona, Crítica, 1999.

Villari, Rosario, Un sogno di libertà. Napoli nel declino di un impero, 1585-1648, Milano, Mondadori, 2012.

Williams, Robert Haden, Boccalini in Spain: a Study on his Influence on Prose Fiction of the Seventeenth Century, Menasha, George Banta Publishing Company, 1946. 


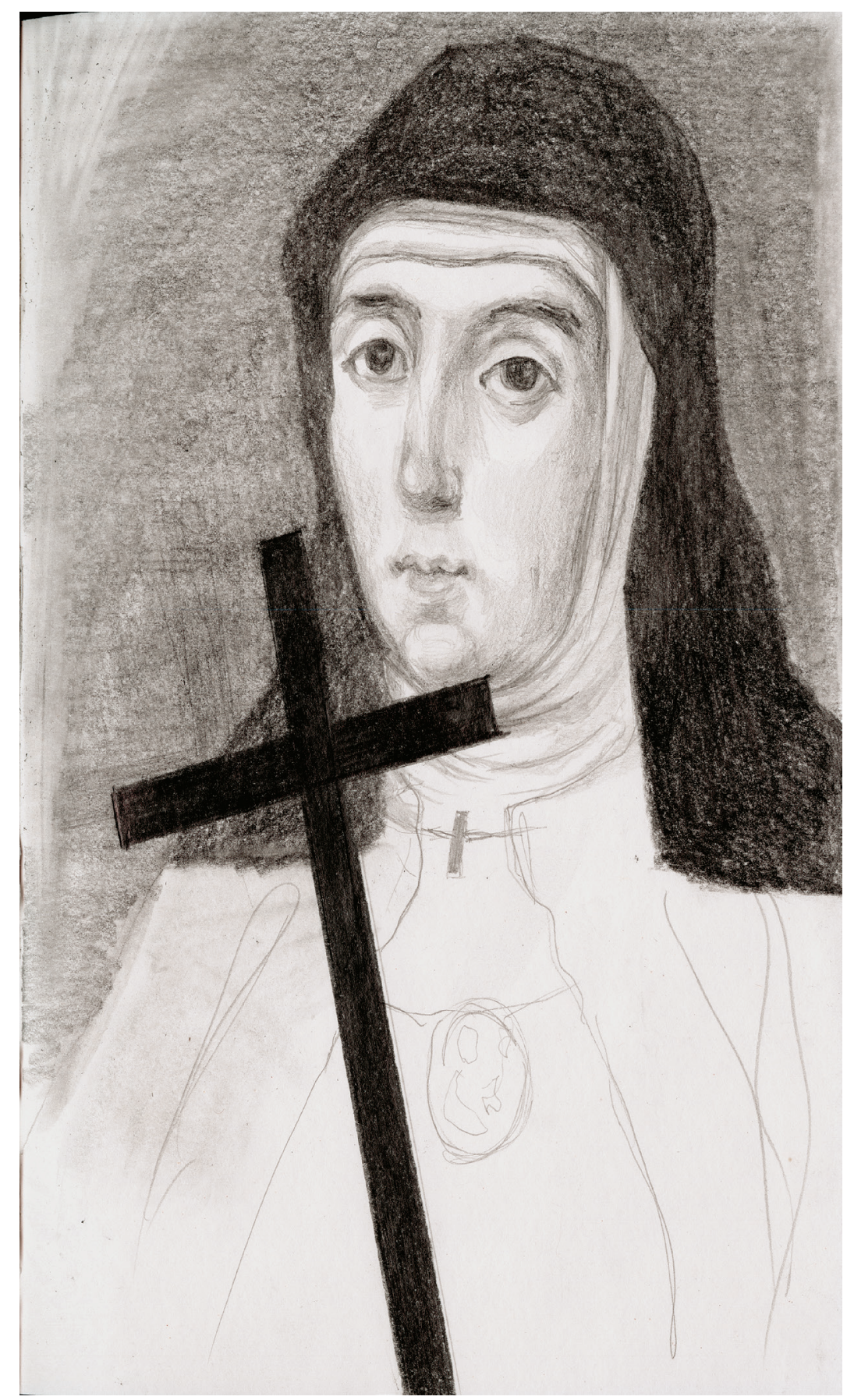


